\title{
Acute Swan-Neck Deformity and Spinal Cord Compression after Cervical Laminectomy
}

\author{
Ralph Rahme, Ghassan Boubez, Alain Bouthillier, Robert Moumdjian
}

Can. J. Neurol. Sci. 2009; 36: 504-506

Cervical kyphosis and swan-neck deformity are an uncommon but well-documented complication of multilevel cervical laminectomy, which typically progress over several months following an initial honeymoon period ${ }^{1,2}$. We report a unique case of acute kyphotic deformity causing spinal cord compression in the immediate post-operative period following cervical laminectomy.

\section{Case Report}

A 42-year-old female patient presented with a five-month history of progressive left-sided weakness, unsteady gait, and bilateral hand clumsiness. Patient's symptoms had been rapidly progressing over the past several weeks resulting in a loss of her ability to ambulate independently. There was no urinary or fecal incontinence. Neurological examination revealed left spastic hemiparesis with 3-4 /5 motor strength in the left upper and lower extremities, generalized hyperreflexia with clonus, and bilateral Babinski sign. The clinical diagnosis of cervical myelopathy was made and magnetic resonance imaging of the cervical spine was performed revealing severe cervical spondylosis with loss of lordosis, marked spinal canal narrowing, and significant spinal cord compression from $\mathrm{C} 2$ to C6 (Figure 1).

Posterior cervical decompression through multilevel C3 to C6 laminectomies was performed. During the procedure, the laminae of C2 were partially exposed by subperiosteal dissection of the paraspinal muscles. Given the preoperative loss of lordosis, noninstrumented fusion of the facet joints from $\mathrm{C} 2$ to C7 using onlay morselized autologous bone graft was performed. Therefore, although facets were preserved, their capsules were completely resected. Blood pressure was maintained at adequate levels during the whole procedure and there were no intraoperative complications. The patient tolerated the surgery very well and was extubated and transferred to the floor.

On the first post-operative day, the patient exhibited rapid neurological deterioration and quadriplegia with a bilateral complete C7 motor and sensory level. Cervical spine MRI was urgently performed and revealed severe swan-neck deformity of the cervical spine with a $30^{\circ}$ kyphotic angle (Figure 2).

The patient was started on high-dose intravenous dexamethasone and taken to the operating room where closed manual reduction was attempted with the Mayfield head holder under fluoroscopy and general anesthesia. However, given our inability to obtain good lordotic alignment, we elected to perform an anterior surgical release followed by a $360^{\circ}$ fusion. Anterior C4-C5 and C5-C6 discectomy and fusion using lyophilized bone allograft and a cervical plate was initially

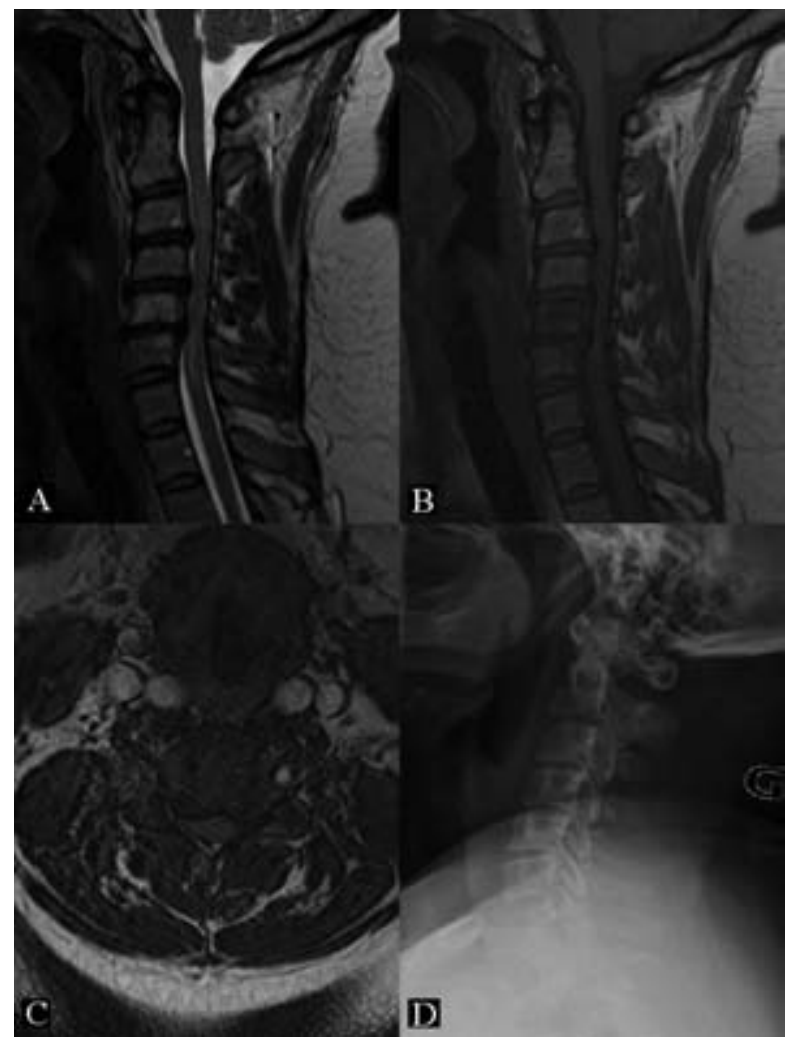

Figure 1: A-D, Preoperative MRI (A-C) and plain radiographs $(D)$ of the cervical spine reveal significant spondylosis and spinal canal narrowing from C2 to C6. The spinal cord is markedly compressed at these levels and exhibits increased signal intensity on T2WI. Note the significant loss of lordosis in the cervical spine.

performed, followed by posterior instrumentation in maximal extension using crossing C2 laminar screws and C3 to C7 lateral mass screws (Figure 3).

Post-operatively, the patient exhibited mild neurological improvement and recovered some of the motor strength in her hands. However, she remained profoundly quadriparetic with a

From the Divisions of Neurosurgery (RR, AB, RM), Orthopedics (GB), Hôpital NotreDame du CHUM, University of Montreal, Montreal, Quebec, Canada.

Received February 3, 2009. Final Revisions Submitted March 6, 2009. Correspondence to: Robert Moumdjian, Division of Neurosurgery, Hôpital NotreDame du CHUM, 1560 Sherbrooke E, Montreal, Quebec, H2L 4K8, Canada. 


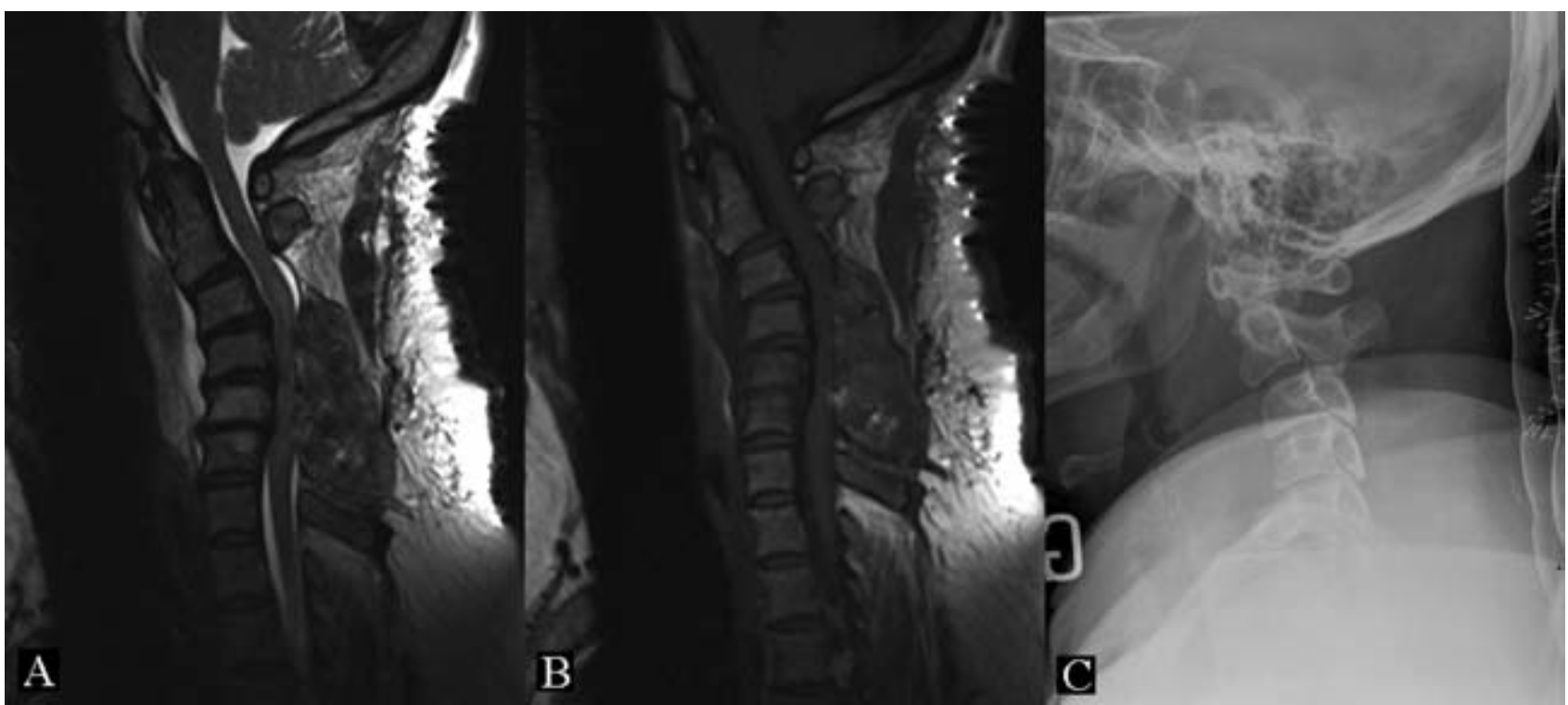

Figure 2: A-C, Post-operative MRI $(A, B)$ and plain radiographs $(C)$ of the cervical spine demonstrate severe swan-neck deformity and draping of the spinal cord over the posterior vertebral bodies.

quasi-complete T1 motor and sensory level, and was eventually transferred to a rehabilitation facility.

\section{DISCUSSION}

The normal cervical spine has a mean lordotic curve of 14 to $20^{\circ 3,4}$. In this position, its weight-bearing axis lies posterior to the vertebral bodies and approximately two thirds of the load is carried by the posterior columns ${ }^{5}$. Following cervical laminectomy, the loss of posterior ligamentous and bony elements can result in loss of lordosis and a forward shift of the weight-bearing axis. This leads to increasing compressive loads on the anterior vertebral body and puts the posterior columns, which have already been weakened by surgery, under considerable tension. Inability of the weakened posterior tension band to withstand the forces needed to maintain alignment eventually results in progressive kyphotic deformity ${ }^{6-8}$.

Kyphotic deformity of the cervical spine is an uncommon but classic complication of multilevel cervical laminectomy ${ }^{1,2,9}$, occurring in approximately $20 \%$ of cases $^{10}$. Although it is generally accepted that adults with normal preoperative spine alignment and no instability who undergo cervical laminectomy rarely experience kyphotic deformity ${ }^{1,9}$, those with preoperative loss of cervical lordosis or kyphosis are at a considerably higher risk $^{10}$. Similarly, because of their immature skeletal system, children and young adults appear to have an elevated risk compared with older adults, particularly when laminectomy is performed for removal of intraspinal tumors ${ }^{9}$. Finally, the number of laminae removed, the extent of laminectomy and facetectomy and facet capsule destruction, and the location of the laminectomy at the craniocervical or cervicothoracic junction, have all been found to predispose to the development of postlaminectomy kyphosis $2,9,11$.

As the kyphotic deformity progresses, the spinal cord may become progressively draped over the posterior vertebral body, resulting in flattening of small feeding vessels to the cord and increased longitudinal cord tension caused by the tethering effect of the dentate ligaments and cervical roots. The combination of spinal cord tension and ischemia results in direct neuronal injury and myelopathy ${ }^{12}$. This typically develops over several months following cervical laminectomy, after an initial honeymoon period $^{1,2}$. To the best of our knowledge, acute spinal cord compression secondary to kyphotic deformity in the immediate post-operative period has not yet been reported.

To prevent the development of postlaminectomy kyphosis, efforts should be made whenever possible to limit the number of laminae removed and extent of facet resection and to preserve the facet capsules ${ }^{9}$. Instability has been noted after resection of as low as $25 \%$ of facets ${ }^{13}$, although most authors warn against resection of more than $50 \%$ of the medial facet complex ${ }^{4,9,14}$. Also, resection of more than $50 \%$ of the facet capsule alone has been found to destabilize the cervical spine ${ }^{15}$. In addition to the posterior ligaments, laminae, and facet joints and capsules ${ }^{1,4,6,13-}$ 15 , the extensor musculature, specifically the semispinalis cervicis and capitis muscles, have been shown to confer stability to the cervical spine and protect against progressive deformity by acting to keep the neck and head in an extended position ${ }^{16}$. Therefore, it has been recommended to preserve the insertion of these muscles onto $\mathrm{C} 2$ and to reattach them when performing cervical laminectomy ${ }^{1,16}$. Laminoplasty has also been proposed as a means to prevent postoperative deformity, although its efficacy remains unproven ${ }^{2,9}$. Finally, for patients with a preexisting spinal deformity and those undergoing extensive bone removal, instrumented posterior fusion should be considered at the time of laminectomy ${ }^{2,9}$. Although no facetectomy was performed in this patient, the preoperative loss of lordosis, multilevel resection of laminae and facet joint capsules, and dissection of semispinalis muscles off the $\mathrm{C} 2$ 


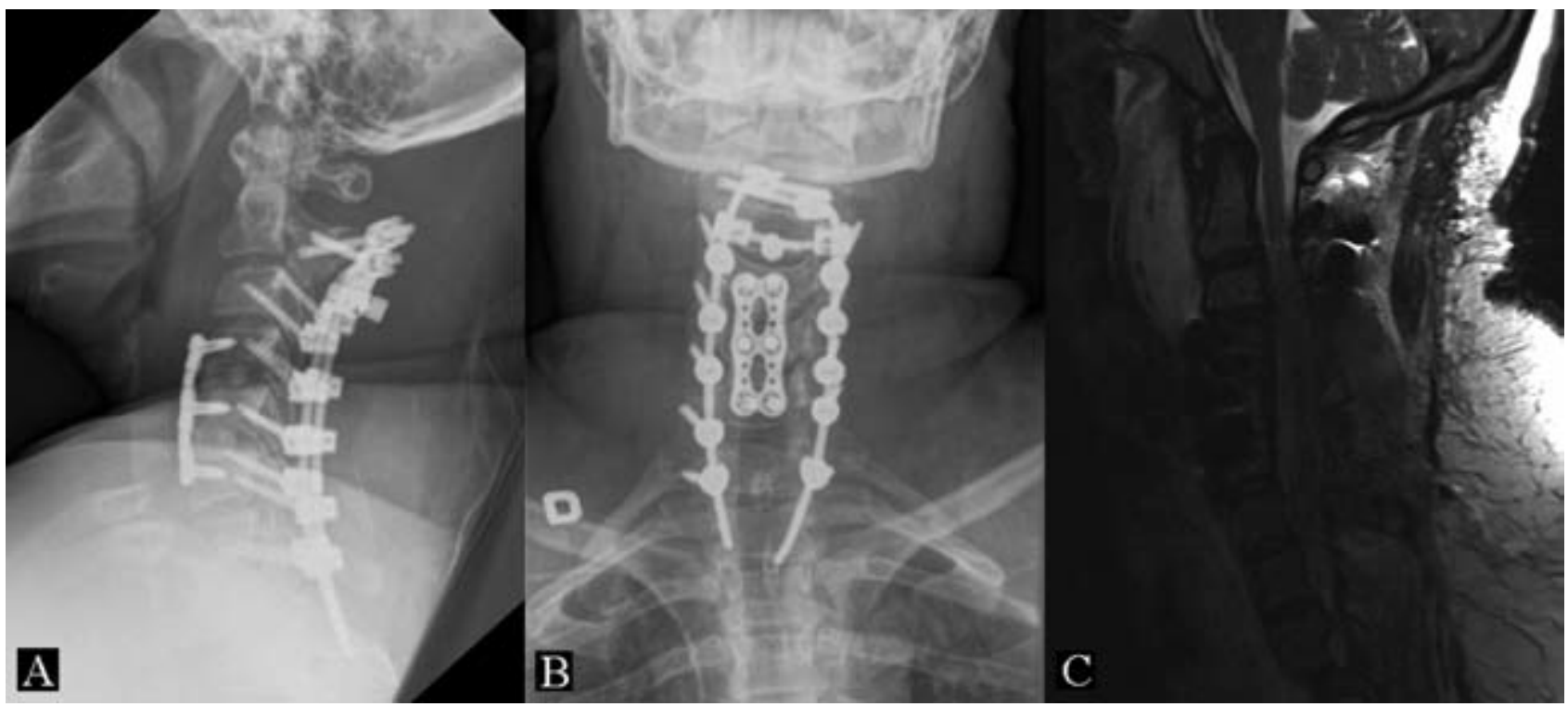

Figure 3: A and B, Plain radiographs show the $360^{\circ}$ cervical fusion performed in this patient. The kyphotic deformity is completely reduced and the cervical spine is back in its straight preoperative alignment. $C$, MRI of the cervical spine demonstrates adequate decompression of the spinal cord.

laminae likely predisposed her to post-operative instability and kyphotic deformity. Therefore, posterior instrumentation at the time of laminectomy would have probably been a better option considering the patient's multiple risk factors for postoperative kyphosis.

Progressive cervical kyphosis should be managed with surgical stabilization and fusion. This can be achieved using an anterior, posterior, or combined anterior-posterior approach ${ }^{1,2,9}$. While the presence of a fixed deformity may necessitate an anterior surgical release through multilevel discectomies or corpectomies, the presence of a severe kyphotic deformity and significant instability, particularly when more than a two-level corpectomy is performed, usually requires the addition of posterior instrumentation to further stabilize the spine and prevent graft extrusion and breakage ${ }^{2,9}$. Posterior fusion alone following closed reduction may be used in the uncommon case of a reducible deformity ${ }^{2}$. In this patient, we elected to perform a $360^{\circ}$ fusion given the marked cervical kyphosis and instability.

In addition to being a potential long-term complication of cervical laminectomy, kyphotic deformity and instability may develop acutely following this procedure in patients with predisposing factors, such as those with preoperative loss of cervical lordosis and those undergoing extensive bone and soft tissue removal, particularly when the semispinalis muscles are detached from $\mathrm{C} 2$. The surgeon should have a low threshold for performing posterior instrumentation in such cases to prevent this potentially catastrophic complication.

\section{REFERENCES}

1. Albert TJ, Vacarro A. Postlaminectomy kyphosis. Spine. 1998; 23: $2738-45$.

2. Deutsch H, Haid RW, Rodts GE, Mummaneni PV. Postlaminectomy cervical deformity. Neurosurg Focus. 2003; 15(3):E5.
3. Gore DR, Sepic SB, Gardner GM. Roentgenographic findings of the cervical spine in asymptomatic people. Spine. 1986; 11: 521-4.

4. Zdeblick TA, Zou D, Warden KE, McCabe R, Kunz D, Vanderby R. Cervical stability after foraminotomy. A biomechanical in vitro analysis. J Bone Joint Surg Am. 1992; 74:22-7.

5. Pal GP, Sherk HH. The vertical stability of the cervical spine. Spine. 1988; 13:447-9.

6. Goel VK, Clark CR, Harris KG, Schulte KR. Kinematics of the cervical spine: effects of multiple total laminectomy and facet wiring. J Orthop Res. 1988; 6:611-9.

7. Panjabi MM, White AA 3rd, Johnson RM. Cervical spine mechanics as a function of transection of components. J Biomech. 1975; 8:327-36.

8. White AA 3rd, Panjabi MM, Thomas CL. The clinical biomechanics of kyphotic deformities. Clin Orthop Relat Res. 1977; (128):8-17.

9. Fassett DR, Clark R, Brockmeyer DL, Schmidt MH. Cervical spine deformity associated with resection of spinal cord tumors. Neurosurg Focus. 2006; 20(2):E2.

10. Kaptain GJ, Simmons NE, Replogle RE, Pobereskin L. Incidence and outcome of kyphotic deformity following laminectomy for cervical spondylotic myelopathy. J Neurosurg. 2000; 93 Suppl 2:199-204.

11. Katsumi Y, Honma T, Nakamura T. Analysis of cervical instability resulting from laminectomies for removal of spinal cord tumor. Spine. 1989; 14:1171-6.

12. Breig A, el-Nadi AF. Biomechanics of the cervical spinal cord. Relief of contact pressure on and overstretching of the spinal cord. Acta Radiol Diagn (Stockh). 1966; 4:602-24.

13. Nowinski GP, Visarius H, Nolte LP, Herkowitz HN. A biomechanical comparison of cervical laminaplasty and cervical laminectomy with progressive facetectomy. Spine. 1993; 18: 1995-2004

14. Raynor RB, Pugh J, Shapiro I. Cervical facetectomy and its effect on spine strength. J Neurosurg. 1985; 63:278-82.

15. Zdeblick TA, Abitbol JJ, Kunz DN, McCabe RP, Garfin S. Cervical stability after sequential capsule resection. Spine. 1993; 18: 2005-8.

16. Nolan JP Jr, Sherk HH. Biomechanical evaluation of the extensor musculature of the cervical spine. Spine. 1988; 13:9-11. 